\title{
Evaluation of LSF based SOFC Cathodes using Cone-shaped Electrodes
}

\author{
Kammer Hansen, Kent; Mogensen, Mogens Bjerg
}

Published in:

ECS Transactions

Link to article, DOI:

$10.1149 / 1.3050387$

Publication date:

2008

Document Version

Publisher's PDF, also known as Version of record

Link back to DTU Orbit

Citation (APA):

Kammer Hansen, K., \& Mogensen, M. B. (2008). Evaluation of LSF based SOFC Cathodes using Cone-shaped Electrodes. ECS Transactions, 13(26), 153-160. https://doi.org/10.1149/1.3050387

\section{General rights}

Copyright and moral rights for the publications made accessible in the public portal are retained by the authors and/or other copyright owners and it is a condition of accessing publications that users recognise and abide by the legal requirements associated with these rights.

- Users may download and print one copy of any publication from the public portal for the purpose of private study or research.

- You may not further distribute the material or use it for any profit-making activity or commercial gain

- You may freely distribute the URL identifying the publication in the public portal

If you believe that this document breaches copyright please contact us providing details, and we will remove access to the work immediately and investigate your claim. 


\title{
Evaluation of LSF based SOFC Cathodes using Cone-shaped Electrodes
}

\author{
K. Kammer Hansen ${ }^{1} \&$ M. Mogensen \\ Fuel Cells and Solid State Chemistry Department \\ Risø National Laboratory for Sustainable Energy \\ Technical University of Denmark \\ DK-4000 Roskilde, Denmark
}

\begin{abstract}
Seven $\mathrm{La}_{1-\mathrm{x}} \mathrm{Sr}_{\mathrm{x}} \mathrm{FeO}_{3-\delta}(\mathrm{x}=0,0.05,0.15,0.25,0.35,0.50,0.70)$
based perovskites were synthesized using the glycine-nitrate method. The $\mathrm{La}_{1-\mathrm{x}} \mathrm{Sr}_{\mathrm{x}} \mathrm{FeO}_{3-\delta}$ compounds were characterized with powder X-ray diffraction and electrochemical impedance spectroscopy on cone-shaped electrodes using a $\mathrm{Ce}_{1.9} \mathrm{Gd}_{0.1} \mathrm{O}_{1.95}$ electrolyte. The activity of the $\mathrm{La}_{1-\mathrm{x}} \mathrm{Sr}_{\mathrm{x}} \mathrm{FeO}_{3-\delta}$ based perovskites towards the electrochemical reduction of oxygen was strongly dependent of the strontium content, the activity being highest for the composition $\mathrm{La}_{0.85} \mathrm{Sr}_{0.15} \mathrm{FeO}_{3-\delta}$. The results indicates that $\mathrm{Fe}$ (III) is the catalytic active specie towards the electrochemical reduction of oxygen in a solid oxide fuel cell on $\mathrm{La}_{1-x} \mathrm{Sr}_{x} \mathrm{FeO}_{3-\delta}$ compounds. The results also show that oxide ion vacancies in the perovskite structure are important for the electrochemical reduction of oxygen. However, the effect of ordering of oxide ion vacancies for the strontium rich compounds can not be excluded.
\end{abstract}

\section{(1) Introduction}

Solid oxide fuel cells (SOFC's) are convenient devices for environmental friendly production of heat and electricity (1). A major obstacle that must be overcome before commercialization of the SOFC is a lowering of the operation temperature (2). In order to achieve this, new electrode materials must be developed. On the cathode side it is known that $\mathrm{Co}$ or Fe-Co based perovskites has the highest performance (3). However, Co or FeCo based perovskites reacts with the commonly used electrolyte, YSZ (Yttria Stabilized Zirconia) forming insulating layers between the cathode and the electrolyte $(4,5)$, lowering the overall performance of the fuel cell drastically. One way to overcome this is to add a barrier layer between the electrode and the electrolyte (6). Another problem with $\mathrm{Co}$ or Fe-Co based cathodes is that they have a large thermal expansion coefficient (TEC) (7). In this study $\mathrm{La}_{1-\mathrm{x}} \mathrm{Sr}_{\mathrm{x}} \mathrm{FeO}_{3-\delta}$ (LSFx) perovskite compounds are studied as cathodes for the electrochemical reduction of oxygen in a SOFC. LSF perovskites are mixed electronic and ionic conductors (8). The electronic conductivity is p-type, and both the electronic and ionic conductivity finds its maximum for the LSF50 perovskite (8).

One method to evaluate new electrode materials is the use of point (or coneshaped) electrodes. Using the cone-shaped electrodes technique has several advantages: The cone and electrolyte is sintered separately, thereby one avoids the formation of a reaction layer between the electrode and electrolyte during processing. The interface is also quite simple and the contact area can be calculated using Newman's formula (9):

\footnotetext{
${ }^{1}$ e-mail: kent.kammer.hansen@risoe.dk
} 


$$
r=\frac{1}{4 R_{s} \sigma^{*}}
$$

where $R_{s}$ is the intercept with real axis in the impedance plot at high frequency, and $\sigma^{*}$ is the specific conductivity of the electrolyte. $\mathrm{r}$ is the radius of the contact between the coneshaped electrode and the electrolyte, from which the contact area can be calculated. Some measurements on ceramic cone-shaped electrodes have already been undertaken (10-14). It seems like this technique is very useful when comparing different electrode materials.

\section{(2) Experimental}

Powders of the La-Sr-Fe perovskites were made by the glycine-nitrate process (15). In short aqueous solutions of the metal-nitrates were mixed in the appropriate ratio in a beaker. Glycine was then added and the solutions were heated on a hot plate until they ignited. The resulting powders were then transferred to alumina crucibles and calcined at $1100^{\circ} \mathrm{C} / 12 \mathrm{~h}$ in air in a box furnace. As metal-nitrates the following nitrates were used $\mathrm{La}\left(\mathrm{NO}_{3}\right)_{3}$ (Alfa Aesar, $99.9 \%$ ), $\mathrm{Sr}\left(\mathrm{NO}_{3}\right)_{2}$ (Alfa Aesar, $99 \%$ ) and $\mathrm{Fe}\left(\mathrm{NO}_{3}\right)_{3}$ (Alfa Aesar, $98 \%$ ). The phase purity of the LSF perovskites was checked by the use of powder X-ray diffraction using a Stoe theta-theta diffractometer equipped with $\mathrm{Cu}_{\mathrm{k} \alpha}$ radiation. The diffractograms were recorded in the interval 20: 20 to $80^{\circ}$. Cylinders for fabrication of the cone-shaped electrodes were made as follows. The powders were pressed in appropriate dies and sintered at $1250^{\circ} \mathrm{C} / 12 \mathrm{~h}$ in air in a box furnace. The resulting cylinders were then machined into cones. The cones had a base diameter of 7.5 $\mathrm{mm}$ and sides with an angle $45^{\circ}$. The electrochemical characterizations of the perovskites were done in a set-up described in (16). The measurements were done in air at temperatures of 800,700 and $600^{\circ} \mathrm{C}$ in the given order. The cone-shaped electrodes were kept at temperature for $24 \mathrm{~h}$ before recording of the electrochemical impedance spectrum. As an electrolyte a pellet of CGO10 $\left(\mathrm{Ce}_{1.9} \mathrm{Gd}_{0.1} \mathrm{O}_{1.95}\right)$ was used. The CGO10 pellet was made by mixing CGO10 powder (Rhodia) with stearic acid and glycerine in a ball mill overnight with EtOH. After drying the powder was pressed in an appropriate die and sintered at $1500^{\circ} \mathrm{C} / 2 \mathrm{~h}$ in a box furnace in air. Before use the pellet was polished. As a counter/reference electrode platinum was used. The platinum was added as a paste (Engelhard) and sintered in-situ at $800^{\circ} \mathrm{C}$. A Solartron 1260 in stand alone mode was used for the electrochemical characterization of the cone-shaped electrodes. The frequency interval spanned was $1 \mathrm{MHz}$ to $0.05 \mathrm{~Hz}$ (or $0.01 \mathrm{~Hz}$ at $600^{\circ} \mathrm{C}$ ). 5 points/decade and ten cycles were measured at each frequency. An amplitude of $24 \mathrm{mV}$ was used throughout. The treatment of the data was done using the PC-DOS program 'equivcrt' by B.A. Boukamp (17). In general the spectra were fitted with three (RQ)'s in series with a series resistance. $\mathrm{Q}$ is a constant phase element with the admittance:

$$
\mathrm{Y}=\mathrm{Y}_{0}\left(\mathrm{j} \omega / \omega_{0}\right)^{\mathrm{n}}
$$

where $Y_{0}$ is a constant, $\omega$ is the cyclic frequency, and $n$ is an exponent. $Y_{0}$ and $n$ is found from the fitting. 


\section{(3) Results}

The results from the powder XRD experiments are summarized in Table 1, where the lattice parameters of the LSF compounds can be found. The lattice parameters are seen to depend on the strontium content. All the strontium containing LSF based perovskites belongs to the orthorhombic crystal system, whereas the strontium free perovskite is cubic.

Table 1. Unit cell parameters for the synthesized compounds obtained from powder XRD data. All the compounds belong to the orthorhombic crystal system except the strontium free ferrite which belongs to the cubic crystal system.

\begin{tabular}{|c|c|c|c|c|c|c|c|}
\hline & LSF00 & LSF05 & LSF15 & LSF25 & LSF35 & LSF50 & LSF70 \\
\hline $\mathrm{A} / n m$ & $39.286(9)$ & $76.40(3)$ & $76.55(3)$ & $76.36(3)$ & $76.32(3)$ & $76.31(3)$ & $76.32(3)$ \\
\hline $\mathrm{B} / n m$ & - & $55.43(3)$ & $55.78(3)$ & $53.348(21)$ & $55.63(3)$ & $55.616(3)$ & $55.606(23)$ \\
\hline $\mathrm{C} / n m$ & - & $53.41(3)$ & $53.39(9)$ & $55.65(3)$ & $53.419(22)$ & $53.44(3)$ & $53.409(20)$ \\
\hline
\end{tabular}

An example of a spectrum from the EIS measurements can be found in Figure 1 together with the result from the fitting. The spectrum consists of three arcs. This is valid for all the compounds.

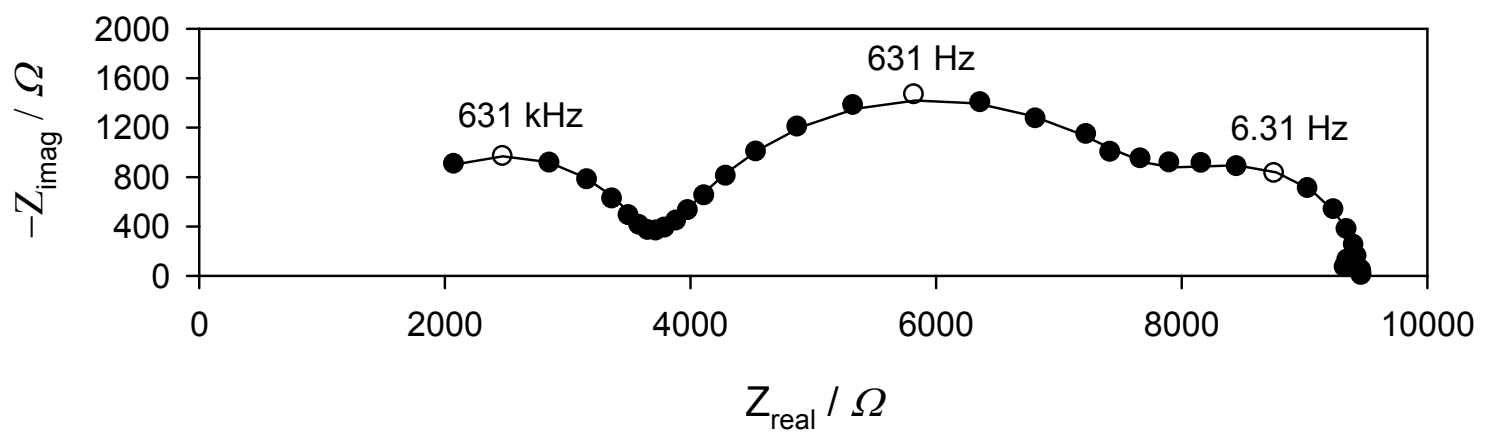

Figure 1. EIS spectrum for the perovskite LSF05 recorded in air at $700^{\circ} \mathrm{C}$. The measured data is plotted as circles and the solid line is the fitted data. The spectrum consists of three arcs.

The ASR values as a function of $\mathrm{Sr}$ content at $700^{\circ} \mathrm{C}$ is shown in Figure 2. It is seen that the total ASR finds a minimum for the compound $\mathrm{La}_{0.85} \mathrm{Sr}_{0.15} \mathrm{FeO}_{3-\delta}$. The highest total ASR value is found for the strontium rich compound $\mathrm{La}_{0.3} \mathrm{Sr}_{0.7} \mathrm{FeO}_{3-\delta}$ with a total ASR of $43.6 \Omega \mathrm{cm}^{2}$ at $700^{\circ} \mathrm{C}$. 


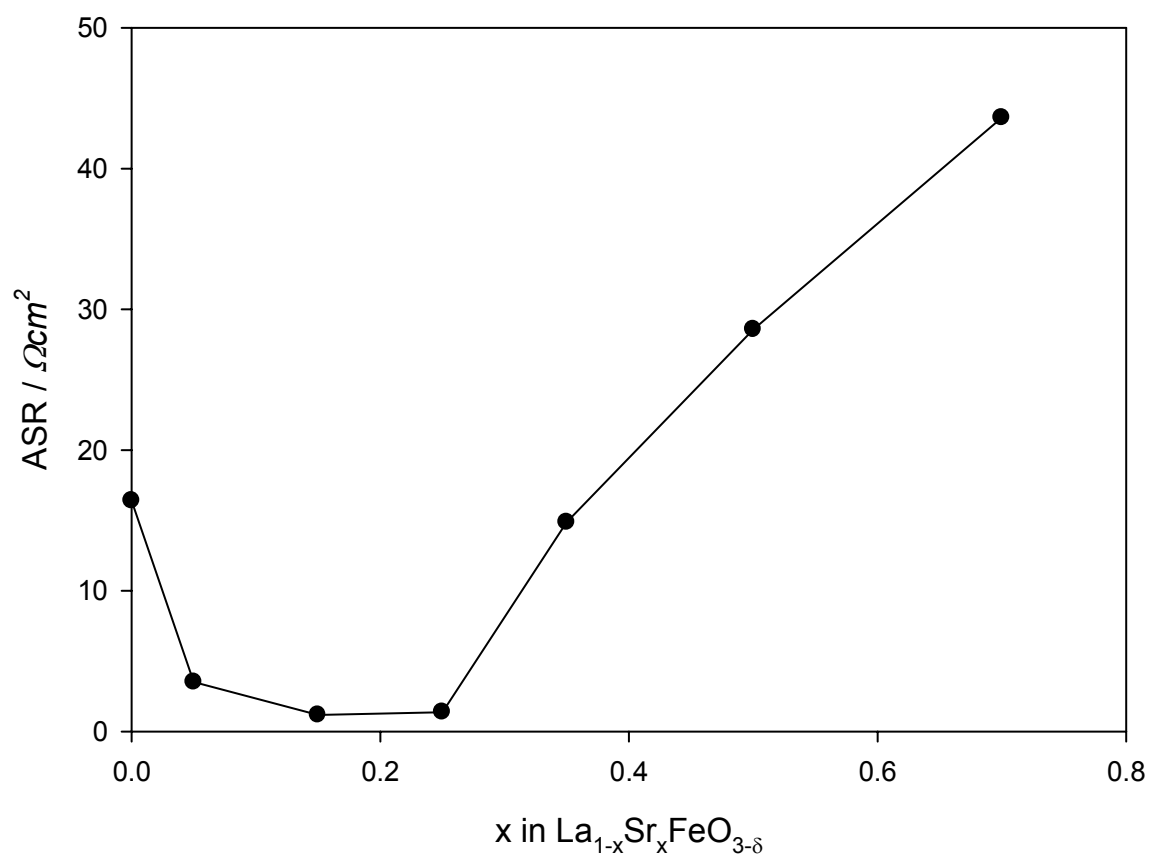

Figure 2. The total ASR of the seven investigated LSF perovskites measured in air at $700^{\circ} \mathrm{C}$ with EIS. The total ASR is seen to be lowest for the perovskite LSF 15 .

The ASR found at the three temperatures can be found in Table 2 .

Table 2. Total ASR of the seven perovskite compounds measured in air at three different temperatures. The ASR values are given in $\Omega \mathrm{cm}^{2}$.

\begin{tabular}{|c|c|c|c|c|c|c|c|}
\hline & LSF00 & LSF05 & LSF15 & LSF25 & LSF35 & LSF50 & LSF70 \\
\hline $600^{\circ} \mathrm{C}$ & 117 & 18.1 & 7.08 & 13.8 & 51.5 & 162 & 223 \\
\hline $700^{\circ} \mathrm{C}$ & 16.4 & 3.51 & 1.16 & 1.36 & 14.9 & 28.6 & 43.6 \\
\hline $800^{\circ} \mathrm{C}$ & 2.39 & 0.76 & 0.20 & 0.50 & 2.02 & 4.37 & 10.8 \\
\hline
\end{tabular}

In Table 3, the contributions of the three individual arcs at $700^{\circ} \mathrm{C}$ are given. They also depend on the amount of strontium in the LSF based perovskites, most noteworthy the low frequency arc.

Table 3. ASR of the three individual arcs for the seven perovskite compounds measured in air at $700^{\circ} \mathrm{C}$.

\begin{tabular}{|c|c|c|c|c|c|c|}
\hline & \multicolumn{2}{|c|}{ High } & \multicolumn{2}{c|}{ Medium } & \multicolumn{2}{c|}{ Low } \\
\hline Compound & ASR & $\mathrm{n}$ & ASR & $\mathrm{n}$ & ASR & $\mathrm{n}$ \\
\hline LSF00 & $0.03 \Omega \mathrm{cm}^{2}$ & 0.94 & $12.2 \Omega \mathrm{cm}^{2}$ & 0.61 & $4.18 \Omega \mathrm{cm}^{2}$ & 0.70 \\
\hline LSF05 & $1.16 \Omega \mathrm{cm}^{2}$ & 0.93 & $1.49 \Omega \mathrm{cm}^{2}$ & 0.37 & $0.86 \Omega \mathrm{cm}^{2}$ & 0.60 \\
\hline LSF15 & $0.52 \Omega \mathrm{cm}^{2}$ & 0.93 & $0.38 \Omega \mathrm{cm}^{2}$ & 0.71 & $0.26 \Omega \mathrm{cm}^{2}$ & 0.78 \\
\hline LSF25 & $0.40 \Omega \mathrm{cm}^{2}$ & 0.85 & $0.74 \Omega \mathrm{cm}^{2}$ & 0.71 & $0.22 \Omega \mathrm{cm}^{2}$ & 0.96 \\
\hline LSF35 & $0.38 \Omega \mathrm{cm}^{2}$ & 0.85 & $3.69 \Omega \mathrm{cm}^{2}$ & 0.52 & $10.8 \Omega \mathrm{cm}^{2}$ & 0.83 \\
\hline LSF50 & $1.67 \Omega \mathrm{cm}^{2}$ & 0.93 & $0.90 \Omega \mathrm{cm}^{2}$ & 0.92 & $26.0 \Omega \mathrm{cm}^{2}$ & 0.56 \\
\hline LSF70 & $1.94 \Omega \mathrm{cm}^{2}$ & 0.91 & $17.4 \Omega \mathrm{cm}^{2}$ & 0.48 & $24.3 \Omega \mathrm{cm}^{2}$ & 0.79 \\
\hline
\end{tabular}




\section{(4) Discussion}

When strontium is substituted for lanthanum in LSF perovskites the following two defect reactions can occur:

$$
\begin{gathered}
2 \mathrm{SrO}+1 / 2 \mathrm{O}_{2}(g) \stackrel{\mathrm{LaFeO}_{3}}{\longrightarrow} 2 \mathrm{Sr}_{\mathrm{La}}^{\prime}+3 \mathrm{O}_{\mathrm{O}}^{x}+2 h^{\bullet} \\
2 \mathrm{SrO} \stackrel{\mathrm{LaFeO}_{3}}{\longrightarrow} 2 \mathrm{Sr}_{\mathrm{La}}^{\prime}+2 \mathrm{O}_{\mathrm{O}}^{x}+V_{O}^{\bullet \bullet}
\end{gathered}
$$

This means that substitution of lanthanum with strontium either will create electronic holes or oxide ion vacancies or both. It has been shown that both the electronic and ionic conductivity increases with increasing strontium content, until $\mathrm{x}$ equal to 0.5 , where after they decreases (8).

The interpretation of the EIS data can be done accordingly to the mechanism suggested by Siebert et al. (18) and others (19). In this mechanism the high frequency arc is normally thought to be due to an exchange reaction (exchange of oxide ions) at the electrode-electrolyte interface. The $\mathrm{n}$ value for this arc is approximately the same for all seven compounds, strongly indicating that this is the same type of reaction occurring on all seven compounds. The magnitude of this arc decreases when $\mathrm{x}$ is increased to 0.35 where after it increases. The equivalent capacity of this arc can be calculated using the following equation (20):

$$
\mathrm{C}_{\omega}=\mathrm{R}^{(1-\mathrm{n}) / \mathrm{n}} Y_{0}^{1 / n}
$$

The capacity of this arc is found to be around $0.5 \mu \mathrm{Fcm}^{-2}$ for all the compounds strongly suggesting that this arc is due to a double layer effect. The value is also in good agreement with the value found in (21) for a double layer capacitance.

The medium frequency arc is attributed to diffusion of oxide anions in the bulk of the electrode $(18,19)$. This arc will therefore depend on the ionic conductivity of the electrode material. It is seen that the magnitude of this arc finds its minimum for $\mathrm{x}$ equal to 0.15 . It is noteworthy that the contribution to the total ASR from this arc is highest for the two compounds LSF00 and LSF70. This is in good agreement with the fact that LSF00 only contains a very low amount of oxide ion vacancies, and that LSF70 contains ordered oxide ion vacancies, with a low oxide ionic conductivity to follow. However, the $\mathrm{n}$-values vary strongly between the different materials. This could either be due to that it is different processes that occur on the seven compounds, or that the mechanism of the ionic conductivity is different on the seven materials. It could also be due to the quality of the data.

The low frequency arc is suggested to be due to a slow redox reaction at the surface of the cathode $(18,19)$. This arc reaches its minimum for the compounds LSF15 and LSF25. This indicates that the oxygen-oxygen bond is most easily broken by these compounds. This implies that the amount of oxide ion vacancies (or the mobility of oxide ion vacancies) plays an important role in the breaking of the oxygen-oxygen bond as the amount of oxide ion vacancies increases with increasing $\mathrm{x}$. But another parameter must also play an important role as the magnitude of this arc increases for $\mathrm{x}$ larger than 0.25 . This parameter could be the amount of Fe(III), or ordering of oxide ion vacancies, 
lowering the mobility of the oxide ion vacancies. It should be noted that ordering of oxide ion vacancies can occur for the compounds with high strontium content leading to a lowering of the mobility of the oxide ion vacancies. This has been shown for the compound $\mathrm{SrFeO}_{3-\delta}$ compared with the compound $\mathrm{La}_{0.5} \mathrm{Sr}_{0.5} \mathrm{FeO}_{3-\delta}$ (22). This parameter is therefore most likely due to the amount of $\mathrm{Fe}(\mathrm{III})$, as the ionic conductivity increases when going from LSF35 to LSF50, but the contribution from the low frequency arc increases. The $\mathrm{n}$ values are strongly dependent on the composition of the electrode material. This could indicate that the breaking of the O-O bond occurs through different elemental reactions on the different electrode materials. Again it should be noted that the variation could be due to the quality of the data. The equivalent capacity of this arc can be calculated as for the high frequency arc. The results can be found in Figure 3.

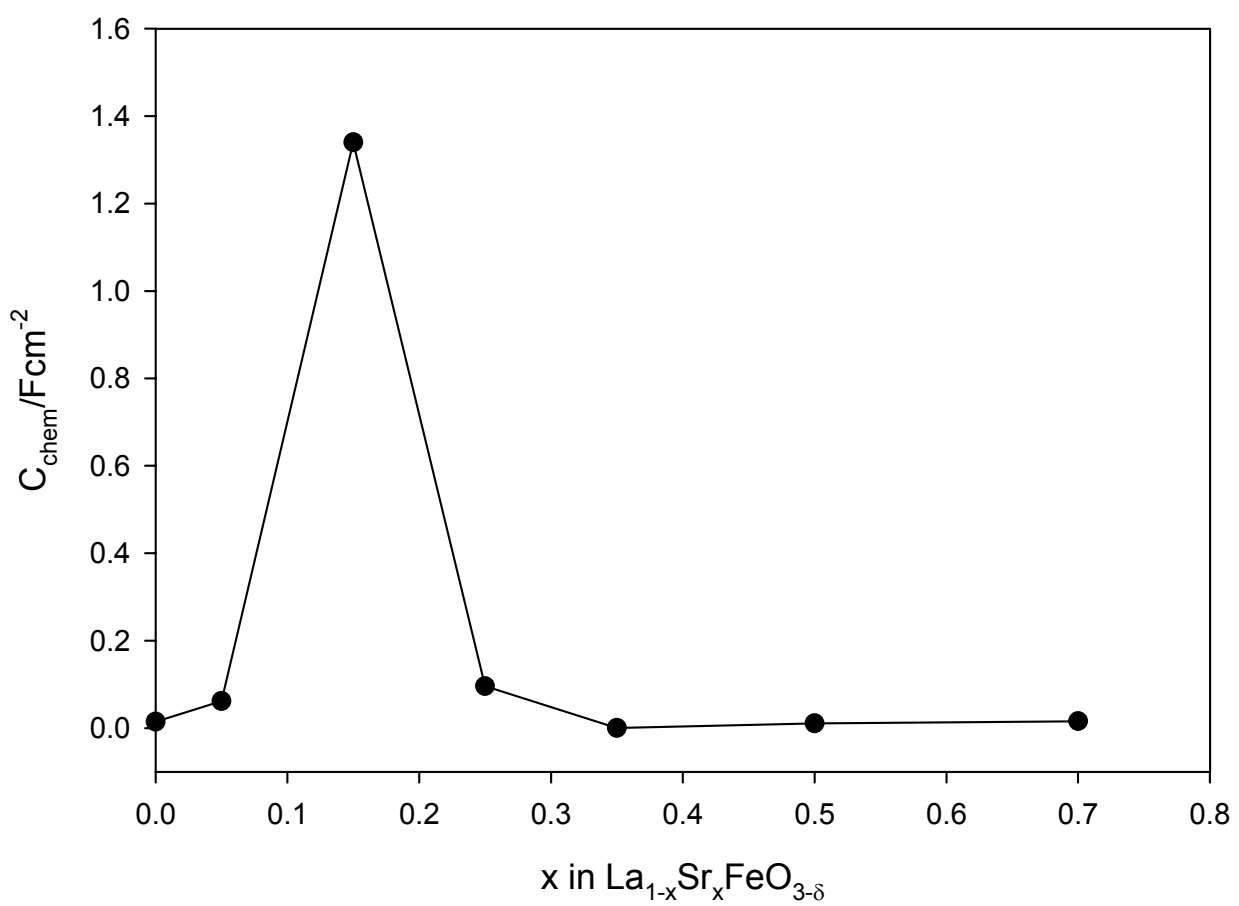

Figure 3. The chemical capacitance of LSF perovskites as a function of the strontium content measured in air at a temperature of $700^{\circ} \mathrm{C}$.

It is seen that the so called chemical capacitance (23) attains a maximum for the compound LSF15, the most active perovskite of the perovskites investigated in this study. It can be of use to compare the electrochemical properties of the ferrites studied here with the electrochemical properties of manganates studied in the literature (24). For the manganites it has been found that the activity towards the reduction of oxygen increases with increasing strontium content (at least until the strontium content is 0.5). For the ferrites the same behavior is not observed. The difference could be due to the fact that the manganates are over-stoichiometric whereas the ferrites are under-stoichiometric with respect to oxygen (25-27). The activity of manganates is apparently less sensitive to the oxidation state of manganese, than ferrites to the oxidation state of iron. 


\section{(5) Conclusion}

The activity of LSF based perovskites as cathodes for the electrochemical reduction of oxygen depends on the amount (or the mobility) of oxide ion vacancies and the amount of $\mathrm{Fe}(\mathrm{III})$. This means that the intermediate compound $\mathrm{La}_{0.85} \mathrm{Sr}_{0.15} \mathrm{FeO}_{3-\delta}$ is the most active towards the electrochemical reduction of oxygen in a SOFC of the LSF compounds investigated in this study. The effect of ordering of oxide ion vacancies for the strontium rich compounds can not be excluded.

\section{(6) Acknowledgements}

Colleagues at the Fuel Cells and Solid State Chemistry Department are thanked for fruitful discussions. Financial support from Energinet.dk through PSO-R\&D-project no. 2006-1-6493 is gratefully acknowledged.

\section{(7) References}

1. N.Q. Minh, T. Takahashi, 'Science and technology of ceramic fuel cells', Elsevier Science B.V. (1995)

2. N.Q. Minh, J. Am. Ceram. Soc., 76563 (1993)

3. J.M Ralph, C. Rossignol, R. Kumar, J. Electrochem. Soc., 150, A1518 (2003)

4. H.Y. Tu, T. Takeda, N. Imanishi, O. Yamamoto, Solid State Ionics, 117, 277 (1999)

5. J.F. Gao, X.Q. Liu, D.K. Peng, G.Y. Meng, Catal. Today, 82, 207 (2003)

6. C.C. Chen, M.M. Nasrallah, H.U. Anderson, J. Electrochem. Soc., 140, 3555 (1993)

7. G.Ch. Kostogloidis, Ch. Ftikos, Solid State Ionics, 126, 143 (1999)

8. M.V. Patrakeev, J.A. Bahteeva, E.B. Mitberg, I.A. Leonidov, V.L. Kozhevnikov, K.R. Poeppelmeier, J. Solid State Chem., 172, 219 (2003).

9. J. Newman, J. Electrochem. Soc., 113, 501 (1966)

10. S.-I. Hashimoto, K. Kammer, P.H. Larsen, F.W. Poulsen, M. Mogensen, Solid State Ionics, 176, 1013 (2005)

11. K. Kammer, Solid State Ionics, 177, 1047 (2006)

12. K. Kammer, L. Mikkelsen, J.B. Bilde-Sørensen, J. Solid State Electrochem., 10, 934 (2006)

13. K.K. Hansen, M. Søgaard, M. Mogensen, Electrochem. Solid-State Lett., 10, B119 (2007)

14. S.-I. Hashimoto, K. Kammer, F.W. Poulsen, M. Mogensen, J. Alloys and Compounds, 428, 256 (2007)

15. L.A. Chick, L.R. Pederson, G.D. Maupin, J.L. Bates, L.E. Thomas, G.J. Exarhos, Matt. Lett., 10, 6 (1990)

16. M. Juhl, M. Mogensen, T. Jacobsen, B. Zachau-Christiansen, N. Thorup, E. Skou, Proc. Electrochem. Soc. 'SOFC IV' 524 (1995)

17. B.A. Boukamp, Solid State Ionics, 20, 31 (1986)

18. E. Siebert, A. Hammouche, M. Kleitz, Electrochimica Acta, 40, 1741 (1995)

19. L.O. Jerdal, 'The Oxygen Electrode Process in Solid Oxide Fuel Cells' Ph.D. thesis NTNU, Norway (1998)

20. T. Jacobsen, B. Zachau-Christiansen, L. Bay, S. Skaarup, in Proceedings of the $17^{\text {th }}$ International Symposium on Materials Science; High Temperature 
Electrochemistry: Ceramics and Metals, ed. F.W. Poulsen et al., Roskilde, Denmark, pp. 29 (1996)

21. N.L. Robertson, J.N. Michaels, J. Electrochem. Soc., 138, 1494 (1991)

22. J. Yoo, A. Verma, S. Wang, A.J. Jacobsen, J. Electrochem. Soc., 152, A497 (2005)

23. S.B. Adler, J.A. Lane, B.C.H. Steele, J. Electrochem. Soc., 143, 3554 (1996)

24. A. Hammouche, E. Siebert, A. Hammou, Mat. Res. Bull., 24, 367 (1989)

25. I.G. Krogh-Andersen, E. Krogh-Andersen, P. Norby, E.M. Skou, J. Solid State Chem., 113, 320 (1994)

26. J. Mizusaki, M. Yoshihiro, S. Yamamuchi, K. Fueki, J. Solid State Chem., 67, 1 (1987)

27. J. Mizusaki, M. Okayasu, S. Yamamuchi, K. Fueki, J. Solid State Chem., 99, 166 (1992) 